Research, part of a Special Feature on Exploring Opportunities for Advancing Collaborative Adaptive Management (CAM): Integrating Experience and Practice

\title{
Intermediate Collaborative Adaptive Management Strategies Build Stakeholder Capacity
}

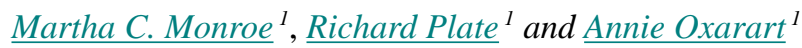

ABSTRACT. Efforts to implement collaborative adaptive management (CAM) often suffer from challenges, such as an unwillingness of managers to share power, unresolved conflicts between stakeholders, and lack of capacity among stakeholders. Some aspects considered essential to CAM, e.g., trust and stakeholder capacity, may be more usefully viewed as goals for intermediate strategies rather than a set of initial conditions. From this perspective, intermediate steps that focus on social learning and building experience could overcome commonly cited barriers to CAM. An exploration of Springs Basin Working Groups, organized around major clusters of freshwater springs in north Florida, provides a case study of how these intermediate steps enable participants to become more reasonable and engaged. This strategy may be easily implemented by agencies beginning a CAM process.

Key Words: collaborative adaptive management; Florida USA; public participation; Reasonable Person Model; social learning; stakeholder capacity

\section{INTRODUCTION}

Adaptive management represents an institutional response as resource management evolves from static, linear models of species or issues to social-ecological models that involve dynamic, "messy" relationships and less predictable conditions. It has become the strategy of choice to address ecosystem complexity and uncertainty through iterative steps of learning by doing, i.e., managing by experimenting, monitoring, and incorporating results into future policies (Walters and Holling 1990). Because managers cannot know with certainty the response of a complex social economic system, they should allow for adjustments to policy as more information is acquired. However, because social-ecological systems are also affected by culture, history, and economics and involve multiple stakeholders, engaging only resource managers and scientists in the learning-by-doing process can limit the effectiveness of the management system (Olsson et al. 2004a, 2004b).

Adaptive comanagement, also known as collaborative adaptive management (CAM), adds these stakeholders to the scientific deliberations through power sharing, capacity building, and learning strategies. Proponents of CAM argue that this strategy can increase the resilience of a system by improving our ability to perceive and understand responses of a social-ecological system and to react to those changes in a timely and appropriate way (Olsson et al. 2004a). The benefits of comanagement with local stakeholders include access to a greater diversity of knowledge and a greater chance of compliance with regulations that arise from group recommendations (Davos 1998, Schindler and Cheek 1999, Olsson and Folke 2001). Teams of scientists, agency experts, and community members use a variety of strategies, such as workshops, multistakeholder processes, social learning, communities of practice, and institutional commitments of time and resources, to establish priorities, craft management plans, and monitor changes in resources (Daniels and Walker 2001, Keen et al. 2005, Pahl-Wostl et al. 2007, Flitcroft et al. 2009, Rodela 2011). Such activities necessitate that participants have a strong understanding of the system they are managing and a healthy ability to work together.

A recent Delphi study added structure to the growing interest in CAM by asking experts to identify core components, research directions, barriers to implementation, and criteria for successful CAM efforts (Plummer and Armitage 2007). The 30 respondents agreed that the most important core components of CAM are its adaptive nature, learning, communication, sharing of power, and shared decision making. A workshop expanded on these concepts by stressing the importance of multiple sources of knowledge, power sharing, inclusion of users, multiple levels of organizations, social capital, and values/vision. The group's response to the question of key challenges or barriers to CAM resulted in agreement that the following are of greatest importance: (1) unwillingness and inflexibility of the state and resource managers to share power and power asymmetries among those involved; (2) insufficient commitment of resources, e.g., financial, human, technical, etc.; (3) group dynamics, i.e., preconceived attitudes about stakeholders, unresolved conflicts and defensiveness, mistrust, domination of particular interests; and (4) lack of capacity and information asymmetries (Plummer and Armitage 2007).

The addition of community stakeholders to the adaptive management process is critically important. At the same time, their inclusion is also the source of most, if not all, of the above 
Table 1. Springs Basin Working Groups (SBWG) managed by Florida Department of Environmental Protection (DEP).

\begin{tabular}{lcccc}
\hline \hline Working Group & $\begin{array}{c}\text { Year Funding by DEP } \\
\text { Began }\end{array}$ & Number of Interviewees & $\begin{array}{c}\text { Number of people on } \\
\text { mailing list }\end{array}$ & $\begin{array}{c}\text { Number of Survey } \\
\text { Respondents }^{\ddagger}\end{array}$ \\
\hline Jackson Blue & 2005 & 4 & -- & -- \\
Ichetucknee & 1995 & 6 & 188 & 45 \\
Wakulla & 1992 & 6 & -- & -- \\
Silver Springs & 1999 & 6 & 205 & 23 \\
Rainbow & 2008 & 6 & 265 & 37 \\
Santa Fe & 1998 & 7 & -- & -- \\
Total & & 35 & 658 & 105 \\
${ }^{\dagger}$ A portion of each list is duplicated on at least one other list. & & & \\
${ }^{\ddagger}$ Only three working groups were contacted with the survey. & & \\
\hline
\end{tabular}

challenges. Although the context of the resource issue might be associated with certain barriers, the lack of capacity and information, as well as attitudes and mistrust suggest a core challenge related to knowledge, skills, and a common experience of interaction. These challenges suggest that social learning is an important goal to facilitate stakeholder participation (Pahl-Wostl 2006, Muro and Jeffrey 2008, Collins and Ison 2009). Collaborative adaptive management opportunities might occur more frequently and more successfully if intermediate strategies that emphasize information exchange, capacity building, and trust could prepare stakeholders and experts for a future role in adaptively comanaging a resource.

A variety of strategies have been used to increase awareness and understanding among stakeholders. For example, enabling the public to provide input to recommendations through an educational program such as a community forum has the benefits of sharing information, addressing misconceptions, and offering access to experts while providing a report of opinions and perspectives to decision makers (Monroe et al. 2009). Although these strategies are not typically considered part of the CAM toolbox, they could be used as an intermediate step to prepare stakeholders for a CAM role, especially if they enable more people to be more informed and comfortably engaged in local issues. They also help build capacity for individuals who wish to become more involved in decisions, if such a structure is available. If these participants were invited into a formal CAM process, some of the limitations noted by Plummer and Armitage (2007) may be less significant.

The importance of building understanding and capacity for engagement and creating avenues for that engagement are highlighted in the Reasonable Person Model (Kaplan and Kaplan 2009). Recognizing that individuals do not always exhibit rational behavior in the context of social-ecological systems, Kaplan and Kaplan (2009:330) focus on how best to encourage reasonable behavior, which includes among other things "cooperation, constructive activity, and civility." In this model, three interdependent factors enhance the capacity of people to engage in solving environmental problems: building mental models, being effective, and being able to take meaningful action. The factors are based on the requisite need for information to build sufficient mental models of the problem, the solutions, and a possible path to achieve resolution. Although individuals are capable of learning on their own, engaging with others may help people to gain (1) information they may not have known they needed, (2) trust in others (Keen et al. 2005), (3) problem-solving strategies, and (4) the satisfaction of participating in something bigger than themselves (Kaplan and Kaplan 2009).

We took a case study approach to explore a type of intermediate CAM strategy represented by the Springs Basin Working Groups (SBWG) in northern Florida, United States through the lens of the Reasonable Person Model (RPM). These multistakeholder groups formed around major clusters of freshwater springs. The springs are a highly valued, natural resource in the region, but their quality has declined in recent years with increased demand for drinking water, recreation, and land-use changes. Thus farmers, anglers, outfitters, water bottlers, municipalities, industries, planners, elected officials, and nearby residents have a stake in the health of the springs. After several early working groups formed as a grassroots effort, six groups were ultimately funded by the Florida Department of Environmental Protection's Springs Initiative to enable members of the public, environmental organizations, agency staff, and technical experts to share information and discuss solutions to protect springs (Florida DEP 2007; Table 1).

Despite the appearance of a collaborative approach to resource management, the working groups have no decision making authority, nor do they have the bylaws or officers to make decisions. They are not engaged in exploring or making management recommendations, nor are they in a position to collect data and monitor results. Although the meetings are open to anyone, they attract only people who are seriously interested in protecting water quality. As a result, key 
stakeholders, e.g., business leaders, are noticeably absent. The single-minded focus, the flexible membership, and the lack of power to create recommendations that define the SBWG exclude them from consideration as a CAM process. However, SBWG members feel the groups are extremely effective at providing long-term protection of the springs and other benefits as well. To better understand the success and potential role of the SBWG model, we used the RPM to frame our questions to explore how participants believe SBWGs contribute to springs management. We used the mixed methods of interviews, observations, and a survey to investigate the SBWG model of engaging stakeholders in resource management.

The interview and observation portion of the study was designed primarily to understand the operation and focus of the working groups. In the survey phase of the study, we focused more directly on how SBWG participants viewed the benefits and impacts of the SBWGs on themselves and on their ability to create positive change. Survey questions were designed using the Reasonable Person Model (Kaplan and Kaplan 2009) with a primary focus on assessing how participation in the SBWGs might affect the characteristics that would help individuals play a role in the management of springs. To that end, we focused on members' (1) perceptions of their knowledge and understanding of the springs system, i.e., mental models; (2) ability to engage in discussions of springs management and work with others to effect positive change, i.e., being effective; (3) perceptions about the community-level impacts of the group, i.e., meaningful actions; (4) level of activity in their working group; and (5) perceptions of trust of other working group members.

\section{METHODS}

We began our data collection with open-ended interviews with each SBWG coordinator to better understand the goals and basic organization of the group. In addition, we observed at least one meeting for each of the six working groups to learn about the meeting format, presentations, participants, and atmosphere. Based on the coordinator interviews and observations, we developed an interview guide of 26 openended questions and a card-sorting exercise (Kearney and Kaplan 1997) that allowed respondents to select items that explained the health of the springs. This technique allows researchers to measure the degree to which respondents share similar ideas. Interviewees were asked to identify things that were important to the health of their spring ecosystem. To do this, they chose items, e.g., fertilizer, septic tanks, water quality, from a stack of 52 cards and were also allowed to add any aspects they felt were missing from the original stack.

A purposeful sample of active members was selected by the coordinator or from lists of volunteers, balancing agency scientists, agency nonscientists, advocacy group members, and citizens. A total of 35 SBWG members participated in interviews ranging from just over 30 minutes to almost 2 hours. Four to seven members were interviewed from each group (Table 1). Audio recordings were analyzed inductively to allow themes to emerge through grounded theory (Patton 1990).

Survey questions were developed to assess the opinions and perspectives of all members of three of the six working groups. The selected working groups had a stable and large membership, consistent leadership, and coordinators who agreed to participate in the survey. The survey was reviewed by two SBWG coordinators and pilot tested with three people similar to working group members. The revised survey included 19 items about their experience with the working group, 15 items about perceived outcomes of the working group, and 2 demographic questions. The survey was administered through an online website with the working group coordinators sending email requests to their entire list to participate. Two to three email reminders were sent over a four-week period.

\section{OBSERVATION AND INTERVIEW RESULTS}

Our observations and interviews confirmed that the six working groups share several common characteristics, and the members uniformly agree they are valuable organizations that promote the health of springs. A part-time coordinator provides the organizational framework, prepares the agenda, and leads quarterly in-person meetings. The one-day meetings are held during the week, are open to the public, and consist of scientific presentations made by experts from federal or state agencies, universities, or private companies, e.g., a presentation on the effect of flood and drought on groundwater flow throughout the springs basin, or new technology available for home septic systems. The information tends to flow from the speaker to the audience, and although there is time for questions for the speaker, there is little room for discussion, especially of opinions, values, or alternative ideas. Questions that were perceived as threatening or challenging were redirected by the coordinator to adopt a more neutral tone.

The meetings regularly included time for updates and announcements by all participants, and sometimes included a field tour. People become working group members by asking the coordinator to add them to the mailing list or by signing in at a meeting. Throughout the year, working group coordinators communicate with the membership through email and website updates. Between 20 and 60 people attend the meetings, though the list of interested members may include over 200 names for each group. Active members tend to represent state agencies, e.g., water management, state parks, geological survey, health, environmental protection; county offices, e.g., planning, environment; environmental NGOs, e.g., Audubon, Save Our Springs; elected municipal officials; and interested residents. Some groups also regularly attract local journalists, water bottlers, or farmers. 
Although the quarterly meetings are the most visible activity, interviewees credited the working groups with conducting a variety of other outreach activities, such as contacting local media, bestowing awards on worthy individuals, and producing informative posters. The coordinator usually conducts these well-received activities, and the general public perceives the SBWGs as trusted sources of important information (D. Alenicheva, unpublished manuscript).

Some of the key attributes of a healthy multistakeholder social learning process, such as diverse perspectives and engaging discussion, are not evident in the SBWG meetings.

Box 1: Interviewees' perceptions of SBWG membership:

- I think most of the people who come to the meetings are pretty sophisticated. These are not J.Q. Public or Joe 6Pack.

- I've never met a person there who doesn't have a similar perspective.

- This is not an opinion forum; it is a science and technology forum. It is a working group of the agencies that is open to the public, but only knowledgeable people are on the invitation list.

Despite or perhaps because of their similarity, members value the working group for opening lines of communication among agency scientists, nongovernmental organizations, and individuals. They believe that by not advocating for any one solution, the format enables agency staff to attend.

In addition, even though the group does not take action, the members credit the working group with large communitylevel changes, such as acquiring public lands and ending wastewater sprayfields in sensitive areas. As one interviewee explains, "We are not in a position that we can be action oriented as a group, but we can disseminate the ability to take action through letting people know what other things are going on." Members strongly believe that offering an opportunity to learn more at working group meetings is in itself a valuable outreach tool for increasing community concern about the springs, changing local regulations and practices, and improving the ecosystems of the springs. For example, a member from the Ichetucknee Springs Basin Working Group attributes broad increased concern about the spring largely because of the efforts of the working group:

Now everyone knows the Ichetucknee has to be looked at as a priority before they can do anything in this county. And that to me is incredible. Anywhere you go, you can talk about springs and people will say, yes, the Ichetucknee. ... The groundwork [that] has been done is invaluable and has changed the whole community.

Because members only intend to gain information and do not expect to provide opinions, most are very happy with the existing format.

Some of the credit for the large community-level changes noted above is because of the agencies and organizations represented at the SBWG meetings, thus enabling participants to accept credit in a very general sense. Because the SBWGs have limited their mission to information dissemination, there has been no assumption that the working groups would monitor these changes to measure potential improvement in the health of the springs. The information exchange, however, has enabled participants to grasp why these changes are important and how the system should be improved.

Table 2 shows the cards selected most frequently by 32 interviewees who completed the card sorting exercise. Even though participants completed the exercise while thinking of different springs, the challenges relating to excess nutrients in the springs seem to be the most pressing to all interviewees. There was broad agreement between agency scientists and citizens on these issues.

Table 2. Percentage of interviewees who identified the concept as important to springs health.

\begin{tabular}{lc}
\hline \hline Concept Card & \% of Interviewees $(\mathrm{n}=32)$ \\
\hline Fertilizers & 88 \\
Nitrates & 85 \\
Septic tanks & 85 \\
Water quality & 81 \\
\hline
\end{tabular}

\section{SURVEY RESULTS}

A total of 105 completed surveys were received. Although this represents only $16 \%$ of the three membership lists, a number of names were duplicated on the three lists, and many people, including the authors, wished to be on the lists to receive information but did not intend to participate. A response bias was highly likely, however, with the bias favoring those who were most active or concerned. Nevertheless, responses were received from individuals who attended most of the meetings $(n=29)$ as well as those who did not attend any $(n=15)$. It was not possible to contact nonrespondents or count duplicate names because the working group coordinators were not able to share their lists. Responses from early $(\mathrm{n}=52)$ and late $(\mathrm{n}$ $=53$ ) responders were significantly different on several basic questions and suggest a nonresponse bias will be in the direction of less engagement. 
Items related to each of the three aspects of the Reasonable Person Model (RPM), building a mental model, being effective, and being able to take meaningful action, were analyzed in two ways. First, we wanted to see if group members felt that the SBWGs were helping them to become "reasonable" as described by the RPM. This was assessed based on responses to Likert-scale questions regarding the three aspects of the RPM. Second, we wanted to see if this effect was stronger among people who attended meetings more often. If the working groups were responsible for increasing these factors, then they might vary with attendance. We report both distributions and correlations for each factor.

The mental model portion of RPM suggests that for people to communicate effectively with each other about an environmental system, they must have a shared understanding of how a system works and a willingness to explore the system further. Several of the survey questions addressed ways in which participation in a working group can influence knowledge. Figure 1 shows responses to four survey items pertaining to how participation at the SBWG meetings affected their understanding of the system. Note that a majority of survey respondents believed the working groups increased their understanding of the springs and of actions needed to restore the springs. In addition, they believed the working groups empowered them to learn more about the springs on their own. However, a key element of social learning, i.e., the ability to alter personal ideas as a result of interactions with people who think differently, was not achieved through the working group, with only $34 \%$ of the respondents agreeing that their participation had altered their ideas. For most of these respondents, participation enabled them to learn more information that strengthened their initial understanding of the springs and made them more comfortable and confident in what they know. Participation does not, however, alter their ideas about the springs. Given the nature of those who attended and how the meetings were conducted, this is not a surprising finding.

The second aspect of RPM, being effective, refers to an individual's ability to contribute to addressing the challenges at hand. When individuals lack the necessary knowledge and skills for understanding the ecological, social, economic, and political systems in which they are working, they can become frustrated by the management challenges within each of these contexts. In addition, people can become frustrated by being inundated with too much information. Effectiveness, then, strikes a balance between having enough information to be competent but not so much as to be overwhelmed. Figure 2 shows results from survey questions designed to assess respondents' perceptions of their individual effectiveness as well as the effectiveness of the working groups. Again, a large majority of respondents felt that being in the working groups has increased their ability to contribute new ideas to the group and made them more aware of how groups can make positive change. In addition, less than one-fifth of respondents reported feeling overwhelmed by the high-level scientific presentations that are common at SBWG meetings.

Fig. 1. Respondent perceptions of impacts regarding mental model building.

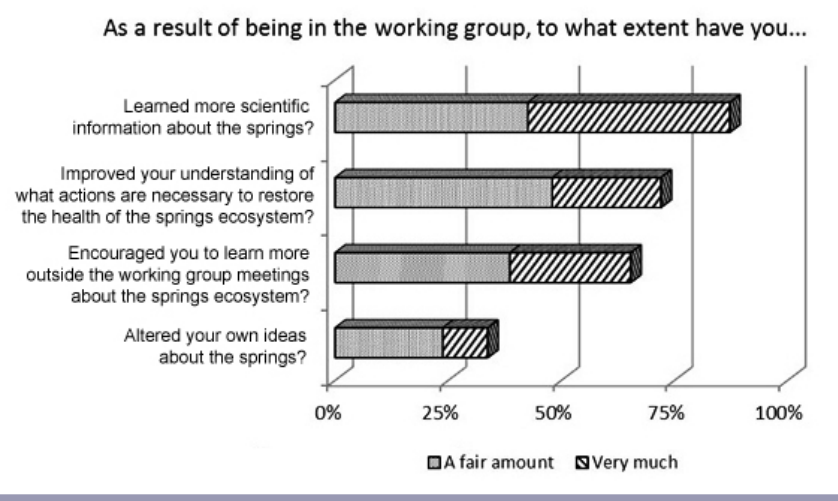

Fig. 2. Respondent perceptions of impacts regarding effectiveness.

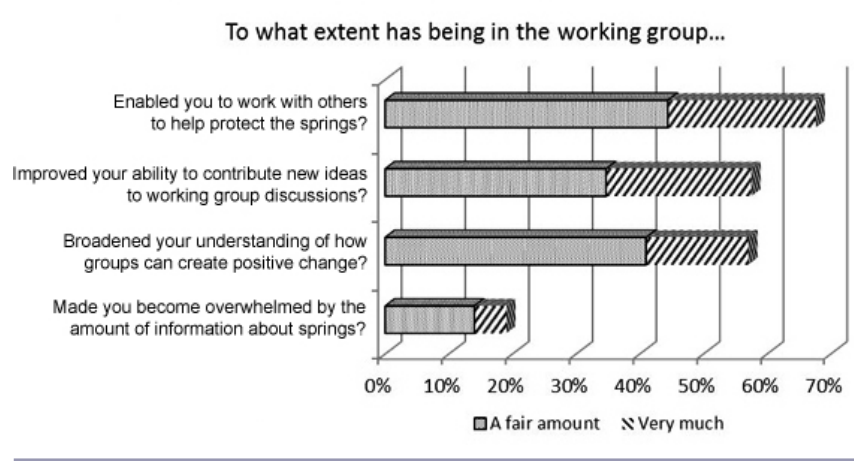

The third aspect of RPM, meaningful action, refers to creating avenues for positive change. In this case, the focus is not on the skills or knowledge of the individuals, but on the structure and conditions of natural and institutional systems that allow for useful participation, as well as models and imagery about how to make those possibilities a reality. Figure 3 shows responses to questions regarding the respondents' perception of the responsiveness of the working group to the individuals and the responsiveness of the larger ecological and social systems to the efforts of the working groups. The first item confirms that respondents believe the system needs to be changed. Subsequent items reflect agreement that the SBWG is an avenue to achieve important changes. Despite the presentation-centered format of meetings, most respondents believed that their input is valued by others. Similarly, despite the lack of decision making authority, most respondents 
agreed that their working group has identified ways to improve the health of the springs and plays an important role in protecting the springs.

Fig. 3. Respondent perceptions regarding meaningful actions.

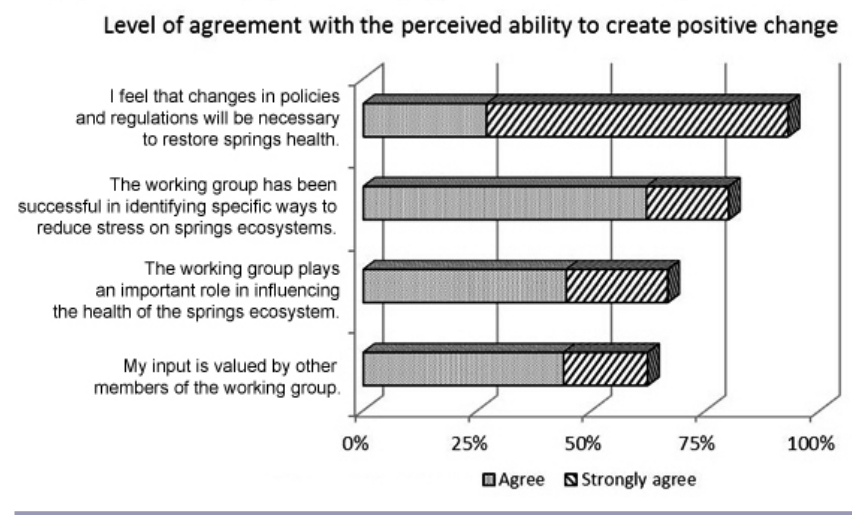

If the SBWG is an effective model for building stakeholder capacity with springs management, we might detect differences between frequent attendees and occasional participants in the criteria that are important for the success of CAM. Because the expert scientists are likely to have greater knowledge about the springs and strategies for affecting change, we focused only on the nonscientist respondents $(\mathrm{n}=$ 76). Mean scores of low attenders (0-2 meetings per year) were compared to those of high attenders (3-4 meetings per year). None of the mental model or meaningful action items showed a notable relationship with attendance rate. For the effectiveness questions, however both "Enabled you to work with others" and "Improved your ability to contribute new ideas" showed a significant relationship with attendance $(\mathrm{p}<$ $0.05)$. In addition, significantly more high attenders agreed with the statements, "I play an integral role in the efforts of the working group" ( $p<0.05)$ and "I enjoy going to working group meetings because I become more informed” ( $p<0.05)$.

In addition, we asked respondents how being involved with SBWGs has affected their level of trust in other working group members. Just over half of respondents indicated that their participation with the working group had increased their level of trust in other members with $38 \%$ responding "A fair amount" and $16 \%$ responding "Very much." Responses to this question did not vary significantly between low and high attenders.

\section{DISCUSSION}

The SBWGs are important opportunities for educating and engaging people who are interested in the protection of springs. Participants express high agreement regarding the key stressors of the system and attribute their participation with working groups to increasing their understanding and skills about how to create positive change in the ecological and institutional systems. These responses suggest that the SBWGs are effective platforms for building mental models, enhancing effectiveness, and creating opportunities for meaningful action. The high values on these RPM factors indicate that the working groups are seen as helping to disseminate information about the springs, build trust among participants, and provide a platform for building the capacity of interested scientists and citizens.

The effect that attendance has among nonscientists' responses to survey items involving ability to work with others, to contribute ideas, and to play an integral role in the group, as well as the enjoyment of becoming more informed, indicates the positive impacts these groups can have.

The weak or absent effect of attendance on other survey responses may be in part because most SBWG members are already knowledgeable about springs, because attending a meeting is not likely to change some items, e.g., altering their ideas about springs, or because the nonscientists do not credit the working groups with their knowledge of how groups can affect change. That information was gleaned elsewhere. Indeed, even those individuals with low attendance at meetings have very positive views about the impacts of the SBWGs, perhaps a function of the nonresponse bias or simply their positive public image. For example, of the low attenders $(n=55), 89 \%$ indicated that their involvement with a SBWG has led them to learn more scientific information about the springs, $80 \%$ feel that the SBWG has been successful in finding ways to reduce stress on the springs, and $51 \%$ have developed a stronger sense of trust in other working group members. The lack of a difference in the perceptions of the success of the working group reinforces the finding from another study that the public believes the working groups are effective and successful (D. Alenicheva, unpublished manuscript).

Nonetheless, this apparent lack of effect of attendance on some responses suggests that changes could be made to the structure of these meetings to increase their impact. Since these data were collected, the SBWGs entered into another stage in their evolution. They were assigned the task of developing a management plan to be submitted to the Florida Department of Environmental Protection (DEP) for review, something that had not previously been part of their mission. The task had the effect of changing the meetings from a series of presentations to a more interactive format in which all meeting participants worked through the steps of developing recommendations and considered who else should be contacted for input. Although this shift is not likely to change the diversity of attendees, it is quite likely to make meeting attendance a greater factor in the learning items described above. Unfortunately, DEP was unable to continue funding the working group coordinators 
after the first drafts were submitted, so the opportunity for SBWG members to contribute to an ongoing management planning process was truncated.

The success of the SBWGs can offer important insights into strategies to reduce barriers to effective CAM. The ability for individuals to be effective depends upon their belief that the community, scientific or institutional, shares the same concern about the springs, intends to protect them, and has the skills to be effective. Having an avenue for meaningful action that enables people to participate in the protection of springs is also essential, and a sense of the actions that others are taking also has an impact. Membership in an SBWG gives respondents an opportunity to become part of a community of people who share their perspective on the health of springs. The working group also provides a path for meaningful action that improves their ability to play a constructive role in the protection of springs.

On a practical level, many members of the public do not have the confidence in their knowledge to contribute to a discussion with agency scientists. Building a shared understanding of the ecosystems of the springs through lecture-presentations and creating a group of people who share a common concern has helped to empower individuals to attend county meetings to speak for the protection of springs, to alert newspaper reporters to changes in the health of the springs, to join events and festivals, and to cosign letters that affect local policy. Although providing information through scientific presentations to a variety of stakeholders does not constitute CAM, it appears to be a very successful strategy for building knowledge among people who are willing and able to take additional actions. The SBWGs excel at building a sense of the collective community of agency scientists and NGO advocates. That the individual achievements of specific group members are seen as a collective success reinforces interest in the group and empowers members. The working groups also enable individuals to find colleagues and avenues for action that suit them. For example, working group members who wish to engage in political action can find opportunities to do so by sidling up to NGO representatives at a meeting.

When reflecting on the larger world of conflict management and strategies to engage the citizenry, the success of the SBWG counters the skepticism that other stakeholders and management officials have expressed about the potential for an CAM structure to work. In light of the types of barriers to CAM described above, Carlsson and Berkes (2005:65-66; italics in original) suggest that focusing too early on formal structural arrangements regarding the process and power of decision making may be counterproductive from a practical standpoint. They prefer to view comanagement as "a continuous problem-solving process, rather than a fixed state." This perspective, they suggest, presents power sharing as "the result, and not the starting point, of the process."
Like other complex systems, collective understanding and action are required to successfully manage Florida springs. Despite features that may seem to weaken their impact, SBWGs appear to represent a reasonable strategy for agencies to begin to identify and engage citizens who care about the resource and are willing to learn more. Because the groups have no authority to make recommendations and coordinators are employed by the agency, there need be no concerns about sharing power and having management decisions challenged. However, working groups empower the NGO community by providing current research results that can be used to better understand the reasons for management decisions and identify new questions that have yet to be explored. They provide an outlet for modest outreach strategies, such as recognizing Springs Champions with annual awards, coordinating festivals celebrating springs, and distributing posters that provide graphic information explaining water movement and threats to the health of springs. Most importantly, these working groups are establishing a foundation for community members to become reasonable participants in the lengthy process of developing, implementing, evaluating, and if necessary, adjusting management strategies for their springs. Many of these small steps are frequently ignored or even dismissed as trivial, yet the sum of these actions can lead to greater support and engagement.

We were struck by the consistent perceptions of the interview and survey respondents about the effectiveness of the SBWG at creating change to protect the springs, while acknowledging the SBWGs' intended lack of action taking. A recent survey of residents of two spring basins suggests this positive perception extends beyond these respondents to the general public, who believe the working groups make good decisions about the springs (D. Alenicheva, unpublished manuscript). Psychologists have long recognized the importance of perceptions to the formation of belief systems (Tversky and Kahneman 1974, Nisbett and Ross 1980) and even actions (Ajzen 1985). In the reinforcing feedback loops of beliefs, attitudes, efficacy, and action, it appears that perceived success empowers participants with confidence in their abilities. If an agency's goal is to prepare participants to engage in CAM, perhaps merely the perception of success is sufficient to help build capacity. These respondents are proud of their successes and comfortably credit their working group with significant impacts.

\section{CONCLUSION}

Although the model provided by the SBWGs is not an example of CAM, it does offer insights regarding how to overcome initial barriers to implementing CAM successfully. The starting point for implementing CAM depends on the context and specifics of the social-ecological systems in question. Nonetheless, the success and popularity of these working groups suggest they could provide some insights for other contexts as well. For agencies and organizations beginning to 
create effective public involvement in resource management, it may be helpful to create a venue that attracts, informs, engages, and supports those who are most interested in the issue. Strategies that incorporate the Reasonable Person Model may be effective at achieving this goal. These intermediate strategies can build knowledge, confidence, and capacity among stakeholders who may then become interested and eligible for the additional work of engaging in CAM. Although it may extend the timeline for CAM activities, agencies may find that this approach helps them overcome some of the barriers to successful CAM identified by Plummer and Armitage (2007). In addition, increased stakeholder capacity may help to facilitate the ongoing process of implementing management actions, monitoring results, and changing management goals as necessary. In the end, developing a group of stakeholders that continues to contribute to CAM in the long term may be well worth the initial time investment.

Responses to this article can be read online at: http://www.ecologyandsociety.org/issues/responses. $\mathrm{php} / 5444$

\section{Acknowledgments:}

We thank the University of Florida Water Institute for providing funding for this study from their PIF Projects; the Florida Department of Environmental Protection who kindly allowed us to embark on this study; Matt Cohen for his insights into framing the study; Lara Colley and John Fort who assisted with data collection and analysis; and Rachel Kaplan and anonymous reviewers who improved the manuscript.

\section{LITERATURE CITED}

Ajzen, I. 1985. From intentions to actions: a theory of planned behavior. Pages 11-39 in J. Kuhl and J. Beckman, editors. Action control: from cognition to behavior. Springer, Heidelberg, Germany.

Carlsson, L., and F. Berkes. 2005. Co-management: concepts and methodological implications. Journal of Environmental Management 75:65-76. http://dx.doi.org/10.1016/j. jenvman.2004.11.008

Collins, K., and R. Ison. 2009. Jumping off Arnstein's ladder: social learning as a new policy paradigm for climate change adaptation. Environmental Policy and Governance 19 (6):358-373. http://dx.doi.org/10.1002/eet.523

Daniels, S. E., and G. B. Walker. 2001. Working through environmental conflict: the collaborative learning approach. Praeger, Santa Barbara, California, USA.
Davos, C. A. 1998. Sustaining co-operation for coastal sustainability. Journal of Environmental Management 52 (4):379-387. http://dx.doi.org/10.1006/jema.1998.0186

Flitcroft, R. L., D. C. Dedrick, C. L. Smith, C. A. Thieman, and J. P. Bolte. 2009. Social infrastructure to integrate science and practice: the experience of the Long Tom Watershed Council. Ecology and Society 14(2): 36. [online] URL: http:// www.ecologyandsociety.org/vol14/iss2/art36/

Florida Department of Environmental Protection. 2007. Florida springs initiative program summary and recommendations. Florida Department of Environmental Protection, Tallahassee, Florida, USA. [online] URL: http:// www.dep.state.fl.us/springs/reports/files/FSIreport2007FINAL. PDF

Kaplan, S., and R. Kaplan. 2009. Creating a larger role for environmental psychology: the reasonable person model as an integrative framework. Journal of Environmental Psychology 29(3):329-339. http://dx.doi.org/10.1016/j.jenvp.2008.10.005

Kearney, A. R., and S. Kaplan. 1997. Toward a methodology for the measurement of knowledge structures of ordinary people: the conceptual content cognitive map (3CM). Environment and Behavior 29(5):579-617. http://dx.doi. org/10.1177/0013916597295001

Keen, M., V. A. Brown, and R. Dyball. 2005. Social learning: a new approach to environmental management. Pages 3-21 in M. Keen, V. A. Brown and R. Dyball, editors. Social learning in environmental management: towards a sustainable future. Earthscan, London, UK.

Monroe, M. C., A. Oxarart, L. McDonell, and R. Plate. 2009. Using community forums to enhance public engagement in environmental decisions. Journal of Education for Sustainable Development 3(2):171-182. http://dx.doi. org/10.1177/097340820900300212

Muro, M., and P. Jeffrey. 2008. A critical review of the theory and application of social learning in participatory natural resource management processes. Journal of Environmental Planning and Management 51:325-344. http://dx.doi. org/10.1080/09640560801977190

Nisbett, R., and L. Ross. 1980. Human inferences: strategies and shortcoming of social judgment. Prentice Hall, Englewood Cliffs, New Jersey, USA.

Olsson, P., and C. Folke. 2001. Local ecological knowledge and institutional dynamics for ecosystem management: a study of Lake Racken Watershed, Sweden. Ecosystems 4(2):85-104. http://dx.doi.org/10.1007/s100210000061 
Olsson, P., C. Folke, and F. Berkes. 2004a. Adaptive comanagement for building resilience in social-ecological systems. Environmental Management 34(1):75-90. http://dx. doi.org/10.1007/s00267-003-0101-7

Olsson, P., C. Folke, and T. Hahn. 2004b. Social-ecological transformation for ecosystem management: the development of adaptive co-management of a wetland landscape in southern Sweden. Ecology and Society 9(4): 2. [online] URL: http:// www.ecologyandsociety.org/vol9/iss4/art2

Pahl-Wostl, C. 2006. The importance of social learning in restoring the multifunctionality of rivers and floodplains. [online] URL: Ecology and Society 11(1): 10. http://www. ecologyandsociety.org/vol11/iss 1/art10/

Pahl-Wostl, C., M. Craps, A. Dewulf, E. Mostert, D. Tabara, and T. Taillieu. 2007. Social learning and water resource management. Ecology and Society 12(2): 5. [online] URL: http://www.ecologyandsociety.org/vol12/iss2/art5

Patton, M. Q. 1990. Qualitative evaluation and research methods. Second edition. Sage, Thousand Oaks, California, USA.

Plummer, R., and D. R. Armitage. 2007. Charting the new territory of adaptive co-management: a Delphi study. Ecology and Society 12(2): 10. [online] URL: http://www. ecologyandsociety.org/vol12/iss2/art10/

Rodela, R. 2011. Social learning and natural resource management: the emergence of three research perspectives. Ecology and Society 16(4): 30. http://dx.doi.org/10.5751/ ES-04554-160430

Shindler, B., and K. Aldred Cheek. 1999. Integrating citizens in adaptive management: a propositional analysis. Conservation Ecology 3(1): 9. [online] URL: http://www. consecol.org/vol3/iss 1/art9

Tversky, A., and D. Kahneman. 1974. Judgment under uncertainty: heuristics and biases. Science 185:1124-1131. http://dx.doi.org/10.1126/science.185.4157.1124

Walters, C. J., and C. S. Holling. 1990. Large-scale management experiments and learning by doing. Ecology 71 (6):2060-2068. http://dx.doi.org/10.2307/1938620 